\title{
In vitro propagation of endemic species Hedysarum chaiyrakanicum (Tuva Republic, Russia) and its widespread congener, $H$. gmelini (Fabaceae)
}

\author{
Anna A. Erst. ${ }^{1 *}$, and Natalia S. Nuzhdina ${ }^{1}$ \\ ${ }^{1}$ CSBG SB RAS, 630090, 101, Zolotodolinskaya st., Novosibirsk, Russia
}

\begin{abstract}
A rare species Hedysarum chaiyrakanicum and a highly polymorphic species $H$. gmelini were first introduced into in vitro culture. It was shown that MS supplemented by $5 \mu \mathrm{M}$ BAP is optimal medium for micropropagation of $H$. gmelini from $90-1$ and 92-1 subpopulations, medium with $1 \mu \mathrm{M}$ BAP is optimal for micropropagation of $H$. chaiyrakanicum from 45-2 subpopulation, and $10 \mu \mathrm{M}$ BAP - for $H$. chaiyrakanicum from 45-1 subpopulation. Seedlings obtained from the seeds of $H$. gmelinii collected from the subpopulation no. 88 demonstrated a higher tendency to callus formation using BAP. It was also found that in vitro culture of $H$. chaiyrakanikum was characterized by a higher reproduction rate then $H$. gmelinii in vitro culture.
\end{abstract}

\section{Introduction}

The steppe community conservation, including monitoring a rare steppe species status and abundance, as well as the development and implementation of modern techniques of plant reproduction and cultivation under ex situ conditions, is a key component in preserving the biodiversity of Northern Asia [1]. Hedysarum chaiyrakanicum Kurbatsky is a narrow-local endemic whose spreading is limited to stony grass dry steppes confined to carbonate rock outcrops of Khaiyrakan Mount (Ulug-Khem Kozhuun, Tuva Republic). Due to overgrazing and limestone mining, the habitat of $H$. chaiyrakanicum is under pressure of destruction. In order to preserve this narrow-local endemic legume species, it was registered in the Red Book of Russia [2] and included in the list of vulnerable species for Tuva Republic [3]. It is noteworthy that despite the extremely narrow range of distribution and low number of individuals the species is characterized by high genomic DNA polymorphism according to ISSR analysis, and possess a karyotype variability: $\mathrm{n}=14,16$ [4]. Meanwhile, $H$. chaiyrakanicum remains one of the least studied plant species in steppe vegetation of South Siberia that allows us to consider the program elaboration for its conservation and reproduction in vitro as an actual direction in frames of the project to preserve steppe landscapes biodiversity in Northern Asia.

*Corresponding author: annaerst@yandex.ru 
Another species, H. gmelini Ledeb., has a wide distribution area and is confined to steppe, mountain-steppe and forest-steppe zones, sometimes observed in the forest and upland belts in the steppes on stony, gravel steep slopes. The species is highly polymorphic and has a significant ecological plasticity [5]; it is a promising forage and medicinal plant [6].

The mail goal of the present work is to develop the protocols of clonal micropropagation the rare species $H$. chaiyrakanicum as an alternative approach to its $e x$ citu conservation, and to create a gene pool collection of highly polymorphic species $H$. gmelini. To achieve it the following tasks were set: 1) to identify the nutrient media composition and in vitro cultivation conditions optimal for shoot initiation in in vitro culture of $H$. chaiyrakanicum and $H$. gmelini ; 2) to investigate the effect of the BAP growth regulator on the morphogenetic potential of $H$. chaiyrakanicum and $H$. gmelini in vitro individuals .

Protocols adopted for clonal micro-propagation of these species should be used to create the bank of in vitro and live collections for introducing and reintroducing valuable genotypes and populations, as well as the plantation cultivating of sweetvetch species characterized by pronounced medicinal properties.

\section{Material and methods}

H. chaiyrakanikum seeds collected by the second author in 2011 in two subpopulations located in the Khaiyrakan Mount (Ulug-Khem Kozhuun, Tuva Republic ) were used to obtain an in vitro tissue culture. To introduce $H$. gmelini into the culture, its seeds collected by Natalia Nuzhdina in 2017 from three Altai populations in were taken.

The seeds were sterilized with $20 \%$ Domestos (20 min. exposure) followed by triple washing in sterile distilled water. Then the non-scarified seeds were sprouted on $0.6 \%$ water agar in a thermostat at $26^{\circ} \mathrm{C}$ in the dark. Sprouted seeds developed at a temperature of $24 \pm 1^{\circ} \mathrm{C}$ under photoperiod conditions: $16 / 8$ hours light/dark, illumination - 2-3 klk. After appearing a pair of real leaves, the seedlings aboveground parts were separated and transferred to the MS [7] supplemented with $0.5 \mu \mathrm{M}$ BAP.

Species mass propagation was carried out by cutting test tube plants into single-node segments and dividing adventitious shoots. The common accepted techniques for the plant tissue and organ cultures were used [8,9].

To assess the morphogenetic potential of the studied species, $H$. chaiyrakanicum and $H$. gmelini micro-shoots were cultured on a medium of $1 / 2$ MS and MS supplemented with BAP growth regulator at concentrations of $0.5 ; 1.0 ; 2.5 ; 5.0$ and $10.0 \mu \mathrm{M}$. Explants were cultured under the conditions: photoperiod - 16/8 hours light/dark, illumination - 2-3 klk, temperature $-24 \pm 1^{\circ} \mathrm{C}$.

We studied the BAP effect on the morphogenetic potential of $H$. chaiyrakanicum and $H$. gmelini during the 4 subcultivations, which has been described as an essential component for $H$. theinum Krasnob. [10, 11], H. grandiflorum Pall. and H. argyrophyllum Ledeb. [12] tissue micropropagation .

\section{Results and Discussion}

The mineral base of MS medium has previously been used to cultivate valuable medicinal species $H$. theinum $[10,11,13]$, and successfully introduced into the practice of cultivating other Hedysarum species [12, 14, 15].

During the experiments it was revealed that at the first cycle of $H$. chaiyrakanicum and H. gmelini subcultivation on the MS supplemented with $0.5 \mu \mathrm{M}$ BAP the developing of 
axillary buds on cotyledon nodes of seedlings was happened without callus formation, i.e. direct shoot regeneration had place (see Table). Earlier for $H$. theinum Krasnob. $[10,11]$ we have found the formation of adventitious buds at the shoot base for the BAP medium only on the 4th and 5th subcultivations; the reproduction rate was $9.2 \pm 1.1 \mathrm{pcs} . / \mathrm{exp}$., which could be treated as an evidence of accumulation the growth regulator in the explant tissues. While in vitro cultivating of $H$. grandiflorum Pall. and $H$. argyrophyllum Ledeb. individuals, Akhmetova and Zaripova [12] have noted that after the first passage, the plant reproduction rate gradually increased, reaching the highest values at the 3rd-5th subcultivations, and then decreased at the 6th-7th passages; the maximum reproduction coefficient was detected at the 5th subcultivation for $H$. grandiflorum, and on the 4th passage - for H. argyrophyllum [12].

We have revealed that $H$. chaiyrakanikum are characterized by a higher reproduction rate in in vitro culture then $H$. gmelini. During the experiments, we have observed differences in the growth and microclonal propagation dynamics at the interpopulation level among the studied species. For propagation of $H$. chaiyrakanicum 45-2 subpopulation, the BAP optimal concentration was $1.0 \mu \mathrm{M}(7.0 \pm 1.8$ pcs./exp.); further increase of the cytokinin concentration in the nutrient medium contributed to callus formation and shoot vitrification. At the same time, it was shown that reproduction rate for $H$. chaiyrakanicum 45-1 subpopulation increased proportionally to BAP concentration and reached a maximum (22.0 \pm 7.6 pcs./exp.) on a nutrient medium with $10 \mu \mathrm{M}$ BAP.

For two populations of $H$. gmelini $90-1$ and 92-1, it was observed that concentration of $10 \mu \mathrm{M}$ BAP leads to callus formation. The maximum plant reproduction rate of $H$. gmelini 90-1 and 92-1 populations was fixed on a medium supplemented with $5 \mu \mathrm{M}$ BAP $(14.6 \pm 8.6$ and $10.4 \pm 4.7$ pcs./exp. respectively). Callus formation was pointed out at all tested cytokinin concentrations from 0.5 to $10 \mu \mathrm{M}$ BAP for $H$. gmelini 88 population.

According to Akhmetova and Zaripova data [12] iIt is noteworthy that the optimal nutrient medium for $H$. grandiflorum shoot formation is MS adding $1.0 \mathrm{mg} / \mathrm{l} \mathrm{BAP}$, the reproduction rate is 4.9. These authors' materials allowed obtaining a maximum reproduction rate equal to 8.0 for $H$. argyrophyllum using MS + BAP $2.0 \mathrm{mg} / 1+\mathrm{NAA} 0.1$ $\mathrm{mg} / \mathrm{l}$. For H. coronarium L., the optimal medium was MS supplemented with $0.4 \mathrm{mg} / \mathrm{l} \mathrm{BAP}$ [16]. While cultivating a narrow-locality endemic of Olkhon Peninsula (Irkutsk Region), $H$. zundukii Peschkova, the BAP concentration of $1 \mathrm{mg} / 1$ was noted as the most effective for plant propagation, but under these conditions, shorter shoots were formed than in media with cytokinin lower or higher content [17]. The authors also noted such a problem of $H$. zundukii in vitro reproduction as shoot strong vitrification in BAP presence.

Thus, we have selected cultivation conditions and nutrient media for in vitro introduction and reproduction of $H$. chaiyrakanicum and $H$. gmelini species. It is shown that the optimal medium for micro-propagation is MS supplemented with $5 \mu \mathrm{M}$ BAP for $H$. gmelini 90-1 and 92-1 subpopulations, $1 \mu \mathrm{M}$ BAP - for $H$. chaiyrakanicum 45-2 subpopulation, and $10 \mu \mathrm{M}$ BAP for 45-1 subpopulation. Seedlings obtained from the seeds of $H$. gmelinii collected from the subpopulation no. 88 showed a high tendency to form callus when using BAP.

The present study will serve as a basis for developing the clonal micropropagation protocols and obtaining stable sterile tissue cultures of $H$. chaiyrakanicum and $H$. gmelini which are necessary to form complex measures using high technologies aimed at ex situ preserving the populations of rare steppe plant species in Siberia.

Table. The influence of the composition of the nutrient medium on the morphogenic response of Hedysarum chaiyrakanicum and $H$. gmelini in vitro cultures

\begin{tabular}{|c|c|c|c|c|c|}
\hline \multirow{2}{*}{$\begin{array}{l}\text { Nutrient } \\
\text { medium }\end{array}$} & \multicolumn{2}{|c|}{ H. chaiyrakanicum } & \multicolumn{3}{c|}{ H. gmelini } \\
\cline { 2 - 6 } & Subpopulation & Subpopulation & Subpopulation & Subpopulation & Subpopulation \\
& $45-1$ & $45-2$ & 88 & $90-1$ & $92-1$ \\
\hline
\end{tabular}




\begin{tabular}{|c|c|c|c|c|c|}
\hline & & & & & \\
\hline $1 / 2 \mathrm{MS}$ & 1 & 1 & 1 & 1 & $2.3 \pm 1.1$ \\
\hline MS & 1 & 1 & 1 & 1 & $1.3 \pm 0.5$ \\
\hline $\begin{array}{c}\text { MS+BAP } \\
0,5\end{array}$ & $3.5 \pm 0.7$ & $1.75 \pm 0.8$ & $2.3 \pm 0.4 * *$ & 1 & $1.2 \pm 0.3$ \\
\hline $\begin{array}{c}\text { MS+BAP } \\
1,0\end{array}$ & $3.8 \pm 1.4$ & $7.0 \pm 1.8$ & $3.6 \pm 1.2^{* *}$ & $2.9 \pm 0.8$ & $1.9 \pm 0.8$ \\
\hline $\begin{array}{c}\text { MS+BAP } \\
2,5\end{array}$ & $6.5 \pm 2.6$ & $2-21^{*}$ & $7.7 \pm 2.5 * *$ & $4.5 \pm 1.1$ & $3.8 \pm 0.9$ \\
\hline MS+BAP 5 & $10.6 \pm 7.6$ & $* *$ & $4.8 \pm 1.5 * *$ & $14.6 \pm 8.6$ & $10.4 \pm 4.7$ \\
\hline $\begin{array}{c}\text { MS+BAP } \\
10,0\end{array}$ & $22.0 \pm 7.6$ & $* *$ & $4.9 \pm 1.2^{* *}$ & $17.6 \pm 6.4 * *$ & $7.8 \pm 5.8^{* * *}$, \\
\hline
\end{tabular}

Note: $*$ - vitrification, $* *$ - callus.

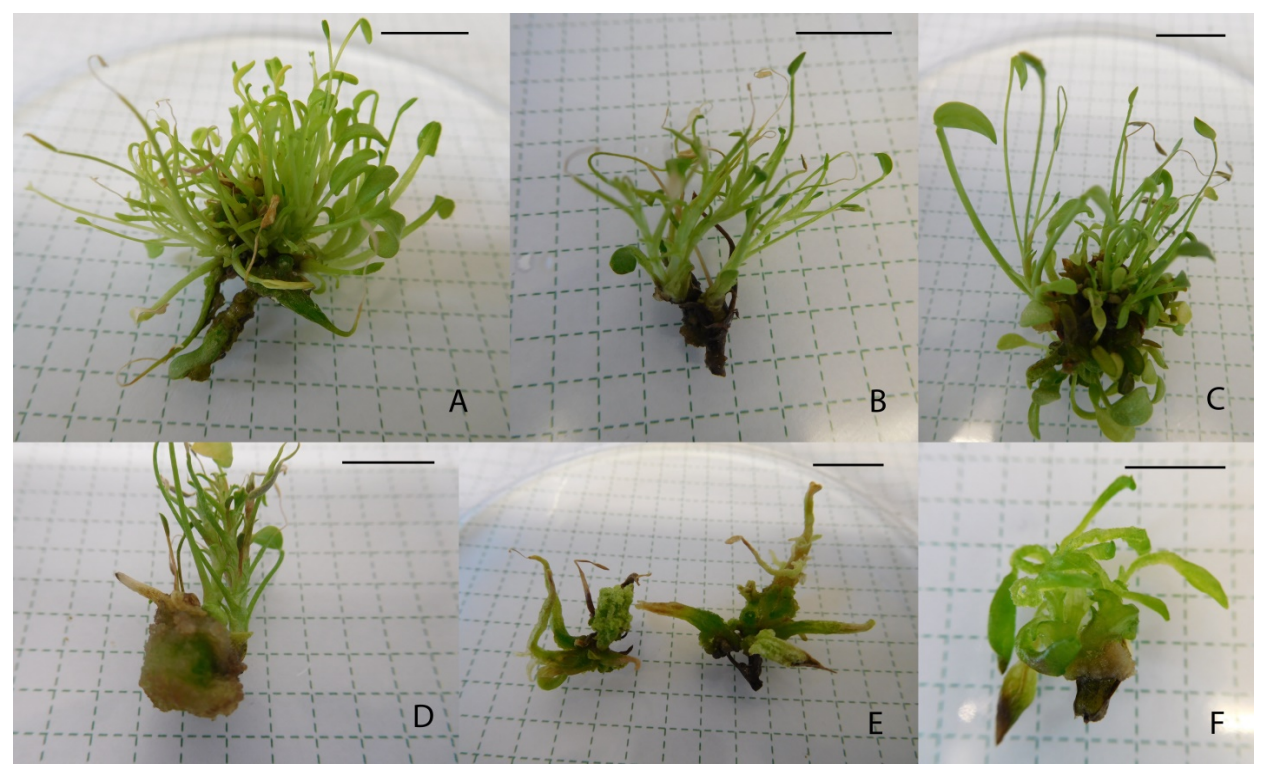

Fig. 1. Hedysarum chaiyrakanicum and H. gmelini plants in in vitro: A. Adventive shoot formation of $H$. chaiyrakanicum in a nutrient medium supplemented with $10 \mu \mathrm{M}$ BAP. B. Adventive shoot formation of $H$. chaiyrakanicum in a nutrient medium supplemented with $1 \mu \mathrm{M}$ BAP. C. Adventive shoot formation of $H$. gmelini in culture medium supplemented with $5 \mu \mathrm{M}$ BAP. D. Callus formation at the base of $H$. gmelini explant in medium supplemented with $2.5 \mu \mathrm{M}$ BAP. E. Callus formation on the surface of $H$. chaiyrakanicum explants in a nutrient medium supplemented with $10 \mu \mathrm{M}$ BAP. F. Vitrification of $H$. gmelini shoots on medium supplemented with $10 \mu \mathrm{M}$ BAP. Bar $1 \mathrm{~cm}$.

This work was supported by the budgetary project of the CSBG SB RAS AAAA-A17117012610051-5. Experimental research was conducted using materials of the Bioresource Scientific Collection of the CSBG SB RAS "Collections of living plants indoors and outdoors USU_440534 (Novosibirsk, Russia).

\section{References}

1. M.J.A.Werger, M.A. van Staalduinen, Eurasian steppes. Ecological problems and livelihoods in a changing world (Springer, Dordrecht, 2012)

2. Kamelin R V et al., Red Book of the Russian Federation (Plants and Fungi) (Moscow, Comrade scientific.ed. KVM, 2008) 
3. S.O. Ondar, D.N. Shaulo, The Red Book of the Republic of Tyva (Animals, Plants and Fungi), (Kyzyl, 2018)

4. N.S. Nuzhdina (Zvyagina), O.V. Dorogina, A.A. Krasnikov, IJEB, 54, 338, 2016

5. V.P. Kurbatsky, Flora of Siberia, 9, 153, 1994

6. E.V. Zhmud, Bulletin of TSPU, 11 (152), 220, 2014

7. T. Murashige, F. Skoog, Physiol. Plant, 15, 473, 1962

8. R.G. Butenko, The culture of isolated tissues and the physiology of morphogenesis in plants (Moscow, Science, 1964)

9. F.L. Kalinin, V.V. Sarnatskaya, V.E. Polishchuk, Methods of tissue culture in plant physiology and biochemistry (Kiev, Science. Dumka, 1980)

10. A.A. Erst, T.V. Zheleznichenko, T.I. Novikova, O. V. Dorogina, E. V. Banaev, Contemp. Probl. Ecol., 7, 67, 2014

11. A.A. Erst, N.S. Zvyagina, T.I. Novikova, O. V. Dorogina, Russian Journal of Genetics, 51, 158, 2015

12. A.Sh. Akhmetova, A.A. Zaripova, Bulletin of USC RAS, 2, 28, 2017

13. M.Yu.Vdovitchenko, I.N. Kuzovkina, H. Patz, B. Schneider, Plant Physiology, 2007. 54, 604, 2007

14. S. Arcioni, D. Mariotti, M. Pezotti, J. Plant Physiol., 121, 141, 1985

15. N.S. Lyapkova, N.V. Khadeeva, S.S. Shain, A.N. Maysuryan, Biotechnology, 1, 55, 1999

16. S. Duque, S. Araújo, P. Fevereiro, A. Barradas, B. Godinho, A.R. Silva, J.P. Crespo, Acta Horticulturae, 409, 2015

17. K. Gamburg, Natural Science, 5, 1289, 2013 